\title{
IMP2, a gene involved in the expression of glucose-repressible genes in Saccharomyces cerevisiae
}

\author{
Tiziana Lodi, Paola Goffrini, Iliana Ferrero and Claudia Donnini
}

Author for correspondence: Claudia Donnini. Tel: +39521 905602. Fax: + 39521905604. e-mail: molgen@IPRUNIV.CCE.UNIPR.IT

Istituto di Genetica, Università di Parma, Viale delle Scienze, 43100 Parma, Italy

\begin{abstract}
Two mutants carrying different deletions of the IMP2 coding sequence of Saccharomyces cerevisiae, $\Delta \mathrm{T} 1$, which encodes a protein lacking the last $26 \mathrm{C}$ terminal amino acids, and $\Delta T 2$, which completely lacks the coding region, were analysed for derepression of glucose-repressible maltose, galactose, raffinose and ethanol utilization pathways in response to glucose limitation. The role of the IMP2 gene product in the regulation of carbon catabolite repressible enzymes maltase, invertase, alcohol dehydrogenase, NAD-dependent glutamate dehydrogenase (NAD-GDH) and L-lactate:ferricytochrome-c oxidoreductase (L-LCR) was also analysed. The IMP2 gene product is required for the rapid glucose derepression of all above-mentioned carbon source utilization pathways and of all the enzymes except for L-LCR. NAD-GDH is regulated by IMP2 in the opposite way and, in fact, this enzyme was released at higher levels in both imp2 mutants than in the wild-type strain. Therefore, the product of IMP2 appears to be involved in positive and negative regulation. Both deletions result in growth and catalytic defects; in some cases partial modification of the gene product yielded more dramatic effects than its complete absence. Moreover, evidence is provided that the IMP2 gene product regulates galactose- and maltose-inducible genes at the transcriptional level and is a positive regulator of maltase, maltose permease and galactose permease gene expression.
\end{abstract}

Keywords: Saccharomyces cerevisiae, glucose derepression, transcriptional regulation

\section{INTRODUCTION}

The compartmentalization of biosynthetic and degradative pathways into distinct subcellular organelles is characteristic of eukaryotic cells. Mitochondria contribute to the biosynthesis of several metabolites and control various cellular processes besides those involved in energy production (for reviews, see Wilkie et al., 1983; de Vries \& Marres, 1987; Attardi \& Schatz, 1988). In the yeast Saccharomyces cerevisiae the interactions between mitochondria and the nucleus are mainly considered in terms of genetic contributions to mitochondrial biogenesis (for reviews, see Attardi \& Schatz, 1988; Grivell, 1989; Tzagoloff \& Dieckmann, 1990). There are also indications

Abbreviations: $A D H$, alcohol dehydrogenase; $E B$, ethidium bromide; $L$ LCR, L-lactate: ferricytochrome-c oxidoreductase; MIC, minimum inhibitory concentration; NAD-GDH, NAD-dependent glutamate dehydrogenase. that the expression of a few nuclear genes strictly depends on either the state or the quality of mitochondria (Parikh et al., 1987; Wang \& Brandriss, 1987; Partaledis \& Mason, 1988). Moreover, two nuclear genes that control interorganelle communication between mitochondria, peroxisomes and the nucleus have been identified (Liao \& Butow, 1993).

We have approached the study of the involvement of mitochondria in various aspects of cell metabolism through the identification of nuclear genes that are required for growth on various carbon sources in the absence of functioning mitochondria (IMP genes) (Algeri et al., 1981 ; Donnini et al., 1992a, b). IMP1, the first gene identified in this way, was shown to be allelic to GAL2. The ability of gal2 null mutants to grow on galactose under respiratory-sufficient, but not under respiratorydeficient conditions, argued that galactose metabolism does not obligatorily involve the induction of the sugarspecific transport system coded by $G A L 2$ and that 
mitochondria-dependent function(s) can substitute for the activity of this system. In particular, galactose uptake depends on mitochondrial supply of ATP (Donnini et al., 1992a).

The IMP2 gene was originally identified as required for maltose, galactose and raffinose utilization in the presence of mitochondrial inhibitors such as ethidium bromide (EB) or erythromycin. Under other conditions, the imp2 mutation can cause pleiotropic defects in cell growth and development, such as poor growth on nonfermentable carbon sources, increased sensitivity to heat shock, and failure of homozygous diploid mutants to sporulate (Donnini et al., 1992b). These findings indicate that IMP2 contributes to a number of yeast cellular processes. The IMP2 gene was cloned by complementation and sequenced, and the deduced amino acid sequence provided a few clues as to its possible cellular function; the predicted IMP2 protein contains a long stretch of acidic amino acids and two putative nuclear localization signals (Donnini et al., 1992b). Furthermore, the low codon bias index of the IMP2 gene (CBI $=0.08$ ) ( $\mathrm{T}$. Lodi, unpublished results) is indicative of a low level of expression and is consistent with the idea that IMP2 may correspond to a regulatory gene.

All of the functions affected by the imp2 mutation are controlled by carbon catabolism (Donnini et al., 1992b). This observation together with the similarities of the pleiotropic defects exhibited by imp 2 mutants and mutants affected in intermediary elements necessary for derepression (Gancedo, 1992; Johnston \& Carlson, 1992) imply that the IMP2 gene product may be involved in the derepression of glucose repressible genes in response to a low glucose concentration. Through the molecular and physiological characterization of various deletion mutants here, we demonstrate that the IMP2 gene does indeed play such a regulatory role.

\section{METHODS}

Strains, media and growth conditions. Saccharomyces cerevisiae strains used in this work include: KD-45B ( $\alpha$ leu2 bis1 IMP2; our collection); its $r b o^{-}$derivative, obtained by three successive treatments on $2 \%(\mathrm{w} / \mathrm{v})$ glucose in the presence of $\mathrm{EB}$ $\left(20 \mu \mathrm{g} \mathrm{ml}^{-1}\right)$; the $\Delta \mathrm{T} 1$ (imp2- $\Delta \mathrm{T} 1::$ LEU2) derivative, obtained as described by Donnini et al. (1992b); 45-4A (a trp1 bis1 ura3 imp2-1), which carries a previously identified spontaneous mutation (Donnini et al., 1992b). Yeast-rich medium (YP) contained Bactopeptone $(2 \%, \mathrm{w} / \mathrm{v})$, yeast extract $(1 \%, \mathrm{w} / \mathrm{v})$ and various carbon sources as specified in the text $(2 \%, \mathrm{w} / \mathrm{v}$, each); glucose was used at $5 \%(\mathrm{w} / \mathrm{v})$ or $0 \cdot 1 \%$ to produce either repressing or derepressing conditions. Exponential-phase cells grown on a reciprocating shaker $(110$ r.p.m. $)$ at $28^{\circ} \mathrm{C}$ in the presence of the indicated carbon sources were collected at $4{ }^{\circ} \mathrm{C}$, washed twice with cold distilled water and shifted to YP media supplemented with the carbon sources indicated in the text. At fixed times (as specified in the text) samples of cells were withdrawn and the $\mathrm{OD}_{600}$, enzyme activities or mRNA content determined. Heat-shock sensitivity was determined as described by Donnini et al. (1992b). Escherichia coli JM83 [ara $\Delta$ (lac-pro AB) rpsL $(=\operatorname{str} A) \phi 80$ lacZ $\Delta \mathrm{M} 15]$ and MC1066 strains (Casadaban et al., 1983) grown in LB or M9 broth (Maniatis et al., 1982) plus ampicillin $\left(150 \mu \mathrm{g} \mathrm{ml}^{-1}\right)$ were used for plasmid amplification.
Transformation. Yeast transformation was performed as described by Ito et al. (1983). Transformants were selected on mineral minimal medium containing $2 \%(\mathrm{w} / \mathrm{v})$ glucose plus the required amino acids at a final concentration of $40 \mu \mathrm{g} \mathrm{ml}^{-1}$ each. Transformation of $E$. coli was performed as described by Mandel \& Higa (1970).

Plasmids. Plasmids pFL44 and Yep13 were kindly provided by F. Lacroute and B. Guiard (Centre de Genetique Moleculaire du CNRS, 91198 Gif-sur-Yvette Cedex, France); plasmid pUC19 was purchased from Pharmacia. The plasmids $\mathrm{pI}-7$ and $\mathrm{pFL} 44 / \mathrm{P}$ were derived from the vectors pUC19 and pFL44, respectively, by filling in the Pst $\mathrm{I}$ site. The plasmid $\mathrm{pFM} 1$ was constructed by cloning the $2.1 \mathrm{~kb} S a l \mathrm{I}-X b a \mathrm{I} I M P 2$ fragment (Donnini et al., $1992 \mathrm{~b}$ ) into the vector pFL44/P. pFM1, linearized by $P_{s t \mathrm{I}}$ digestion and deleted of the $1.6 \mathrm{~kb}$ Pst $\mathrm{I}-P_{s t \mathrm{I}}$ fragment containing the IMP2 ORF, was utilized for transformation of the spontaneous mutant $45-4 \mathrm{~A}$ in the gap repair experiment (see Results).

Gene disruption. The $2 \cdot 1 \mathrm{~kb} S a I-X b a I$ fragment containing the IMP2 gene (Donnini et al., 1992b) was cloned into the vector pUC19 (pI-7). The $1.6 \mathrm{~kb}$ region between Pst I sites, containing the complete ORF, was then deleted and replaced by the $4.1 \mathrm{~kb}$ Pst $\mathrm{I}-$ Pst $\mathrm{I}$ fragment of Yep13 containing the LEU2 gene (pII-DL). pII-DL was cleaved at HindIII and $X b a I$ sites and used to transform the haploid strain KD-45B (leu2 IMP2) to leucine prototrophy. Stable $\mathrm{Leu}^{+} \mathrm{Imp}^{-}$cells were selected on synthetic medium lacking leucine and gene disruption was confirmed by Southern analysis (data not shown).

Preparation of cell-free extracts. Cells were harvested by centrifugation, washed twice with distilled water, resuspended in 1.25 vols extraction buffer (prepared differently for each enzymic determination) and disrupted by vortexing at $4{ }^{\circ} \mathrm{C}$ in the presence of an equal volume of $0.5 \mathrm{~mm}$ diameter glass beads. The resulting suspension was then centrifuged at $5000 \mathrm{~g}$ for $5 \mathrm{~min}$ at $4^{\circ} \mathrm{C}$, the pellet was discarded, and the supernatant was used for enzyme activity measurements.

Enzyme assays. L-Lactate:ferricytochrome- $c$ oxidoreductase (L-LCR) (EC 1.1.2.3) was assayed as described by Ferrero et al. (1984) in the presence of $50 \mathrm{mM}$ L-lactate (lithium salt). NAD-dependent glutamate dehydrogenase (NAD-GDH) (EC 1.4.1.3) and total $\alpha$-glucosidase (maltase, EC 3.2.1.20; isomaltase, EC 3.2.1.10) activities were assayed as described by Grisolia et al. (1964) and Zimmermann et al. (1977). Alcohol dehydrogenase (ADH) (EC 1.1.1.1) activity was measured by following the reduction of NAD at $340 \mathrm{~nm}$ (Hanson \& Jacobsen, 1984). Extracellular invertase (EC 3.2.1.26) was assayed in whole cells (Celenza \& Carlson, 1984) as described by Goldstein \& Lampen (1975).

Isolation and analysis of DNA. Plasmids were purified by standard methods (Maniatis et al., 1982). A previously reported method was used for the preparation of yeast DNA (Nasmyth \& Reed, 1980). Agarose gel electrophoresis and Southern analysis were carried out as described by Maniatis et al. (1982).

Nucleotide sequence analysis. The sequence of the imp2-1 allele was determined with the dideoxy chain-termination method (Sanger et al., 1977) using Sequenase Version 2 (USB). Overlapping deletion subclones were produced by digestion with exonuclease III and S1 nuclease starting from opposite ends of the DNA insert. The sequence of both strands was determined by double-stranded plasmid DNA sequencing using the 17-nucleotide universal and reverse primers. 
RNA analysis. Total RNA isolation and formamide agarose gel electrophoresis were carried by standard methods (Sherman et al., 1982). Blotting to Hybond-N filter and hybridization to the appropriate ${ }^{32}$ P-labelled DNA probes were performed by standard techniques (Maniatis et al., 1982).

\section{RESULTS}

\section{Effect of carbon sources and mitochondrial function on IMP2 gene transcription}

Variations of the steady state levels of the IMP2 transcript in response to either changes of carbon sources or the functional state of the mitochondria were analysed by DNA:RNA hybridization using a $1 \mathrm{~kb}$ HindIII-Pst imp2 fragment (Donnini et al., 1992b) as a probe (Fig. 1). The cellular level of a $900 \mathrm{nt}$ RNA strand, corresponding in size to the ORF of IMP2, was found to be essentially the same in all the carbon sources we have tested (Fig. 1a) and was independent of the functional state of the mitochondria (Fig. 1b).

\section{Complete deletion of the IMP2 coding sequence}

An IMP2 gene disruption which generated a haploid strain, $\Delta \mathrm{T} 1$ (imp2- $\Delta \mathrm{T} 1:: L E U 2)$, carrying an imp2 allele that encodes a protein lacking the last $26 \mathrm{C}$-terminal amino acids (Fig. 2), was previously isolated by Donnini et al. (1992b). This mutation repressed growth on galactose, maltose and raffinose for up to $3 \mathrm{~d}$ in the presence of EB. However, in contrast to a spontaneous imp2-1 mutant, $\Delta \mathrm{T} 1$ grew under all conditions after $5 \mathrm{~d}$ incubation (data not shown). Therefore, to obtain a (a)

(b)

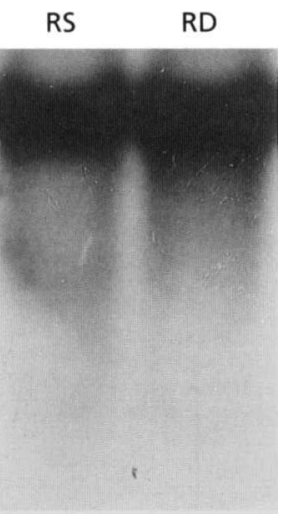

Fig. 1. DNA: RNA blot analysis of IMP2 transcripts. Total cellular mRNA was prepared from strain KD-45B. Cells were collected in the mid-exponential phase of growth in the different conditions described below. (a) Glucose, 2\% (w/v) (lane 1), galactose (lane 2), maltose (lane 3), raffinose (lane 4). Each lane contained $20 \mu \mathrm{g}$ total mRNA. (b) Glucose, $2 \%$, in respiratorysufficient (RS) and respiratory-deficient (RD) conditions. The respiratory-deficient conditions were obtained as described in Methods. Each lane contained $\mathbf{4 0} \mu \mathrm{g}$ total mRNA. Hybridization was carried out with the nick translated plasmid containing IMP2 (see the text) as a probe. Subsequent hybridization with a probe specific for yeast actin RNA confirmed that equal amounts of RNA were loaded in all lanes (data not shown).

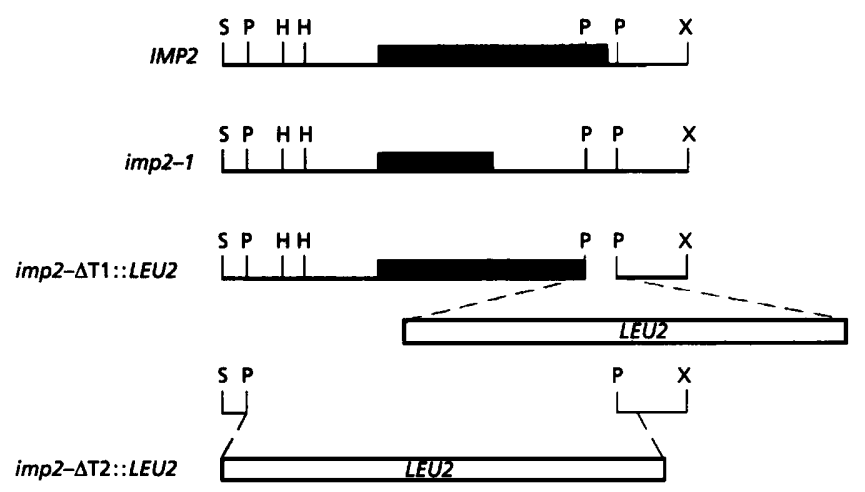

Fig. 2. Schematic representation of IMP2 and mutant alleles. The IMP2 ORF is shown as a black box. The inserted LEU2 gene is shown as an open box. Positions of restriction sites are indicated: H, HindlII; P, Pstl; S, Sall; X, Xbal.

mutant completely lacking the IMP2 coding region a second gene disruption was constructed (see Methods). The haploid strain with the IMP2 gene completely deleted was named $\Delta \mathrm{T} 2$ (imp2- $\Delta \mathrm{T} 2::$ LEU2) (Fig. 2). Similarly to the growth behaviour of the spontaneous mutants carrying the imp2-1 allele, this mutant was unable to grow on maltose, galactose and raffinose in the presence of $20 \mu \mathrm{g} \mathrm{EB} \mathrm{ml}^{-1}$. The minimum inhibitory concentration (MIC) of EB was found to depend on the type of the imp2 allele, both in the presence of the above mentioned carbon sources as well as in media supplemented with $2 \%$ glucose (Table 1). Similar results were obtained with erythromycin, an inhibitor of mitochondrial protein synthesis (data not shown). No differences between mutants and wild-type were observed in the presence of the respiration inhibitor antimycin $\mathrm{A}$ or with the mitochondrial ATPase inhibitor oligomycin (data not shown). The strain carrying a partial deletion of the IMP2 gene $(\Delta \mathrm{T} 1)$ exhibited a MIC value of EB intermediate between that of the wild-type and that of the entirely deleted mutant $(\Delta \mathrm{T} 2)$; the heat-shock sensitivity of the three strains was graded in a similar way (data not shown).

\section{Molecular characterization of the spontaneous imp2-1 mutation}

The different phenotypic behaviour for growth on carbon sources between $\Delta \mathrm{T} 1$ and $\Delta \mathrm{T} 2$, the last being similar to the spontaneous imp2-1 mutant, prompted us to establish the nature of the spontaneous mutation. The chromosomal allele $i m p 2-1$ was isolated on a plasmid by transforming the spontaneous mutant 45-4A (imp2-1 ura3) with a replicating vector containing a double-strand gap corresponding to the ORF of the gene (pFM1) (see Methods). To isolate 'gap-repaired' plasmids that had retrieved the appropriate chromosomal information, $\mathrm{Ura}^{+}$ unstable Imp $\mathrm{Im}^{-}$strains were selected and the insert from the plasmid carrying the chromosomal allele imp2-1 was sequenced. One modification was detected in the ORF; at position +523 , a glutamine codon (CAA) was changed to a nonsense codon (TAA) leading to the production of the truncated protein of 174 amino acids (Fig. 2). 
Table 1. Dependence of EB MIC on allelic status of the IMP2 gene

MIC was determined on plates of YP medium, containing $2 \%$ $(w / v)$ glucose $(G)$, maltose $(M)$, galactose $(G a)$ or raffinose $(R)$, spread with $1 \times 10^{5}$ cells, after $5 \mathrm{~d}$ incubation at $30^{\circ} \mathrm{C}$.

\begin{tabular}{|c|c|c|c|c|}
\hline \multirow[t]{2}{*}{ Relevant genotype } & \multicolumn{4}{|c|}{$\operatorname{MIC}\left(\mu \mathrm{g} \mathrm{ml}^{-1}\right)$} \\
\hline & G & $\mathbf{M}$ & $\mathbf{G a}$ & $\mathbf{R}$ \\
\hline$I M P 2$ & 120 & 40 & 60 & 50 \\
\hline$i m p 2-\Delta \mathrm{T} 1:: L E U 2$ & 70 & 30 & 30 & 30 \\
\hline$i m p 2-\Delta \mathrm{T} 2::$ LEU2 & 50 & 20 & 20 & 20 \\
\hline
\end{tabular}

\section{Derepression and induction of various carbon catabolite pathways in IMP2 deletion mutants}

The subsequent physiological analyses were carried out on the two differently deleted mutants, $\Delta \mathrm{T} 1$ and $\Delta \mathrm{T} 2$, and their isogenic wild-type strain. To verify whether the IMP2 gene is required for derepression of carbon utilization pathways, we measured the growth rates of wild-type and both imp2 deletant strains first cultured at high glucose concentration (5\%) and then switched to YP media supplemented with raffinose, galactose, maltose or ethanol ( $2 \%$ each) (Fig. 3). The wild-type strain exhibited lag times of $4 \mathrm{~h}, 2 \mathrm{~h}$ and $3 \mathrm{~h}$ on raffinose, galactose, and maltose or ethanol, respectively (Fig. 3a, b, c, d). Under all conditions, much longer growth delays were measured for both imp 2 mutants. In addition, both mutants usually showed lower cell yields at stationary phase than those of the wild-type. In all cases, the adaptive lag of $\Delta \mathrm{T} 1$ was shorter than that of $\Delta \mathrm{T} 2$ except when grown with ethanol (32 $\mathrm{h}$ and $24 \mathrm{~h}$, respectively) (Fig. 3d). Therefore, the IMP2 gene appears to influence derepression under all tested conditions.

Both mutants and the wild-type displayed very similar growth curves in all conditions when cells were pregrown either under derepressing conditions (ethanol) or under inducing conditions (galactose, maltose or ethanol) (data not shown). Therefore, IMP2 does not appear to influence induction or growth efficiency on various carbon sources.

It is known that alteration of mitochondrial function results in a delay in adaptation to growth on galactose, maltose and raffinose by affecting cell permeability (Wilkie et al., 1983). To determine if the negative effect on sugar utilization was due to an inhibitory effect of the imp2 mutation on mitochondria, we analysed the growth behaviour of the $r h o^{-} I M P 2$ isogenic strain KD-45B. Under growth conditions identical to those previously applied to the imp2 mutants, this strain exhibited a lag of $38 \mathrm{~h}$ on raffinose, $20 \mathrm{~h}$ on galactose and $6 \mathrm{~h}$ on maltose
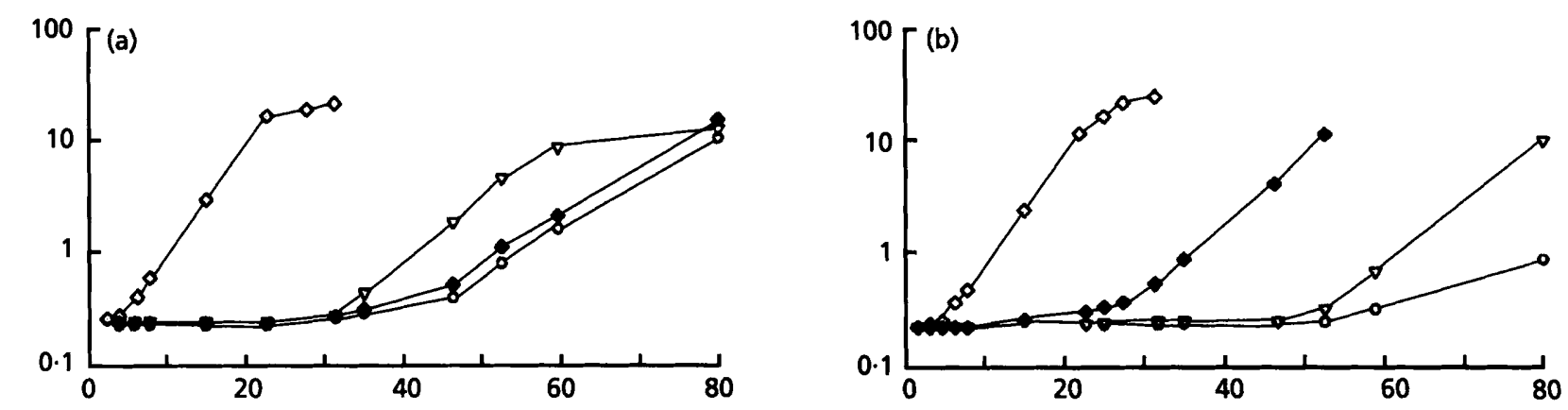

\&ิ
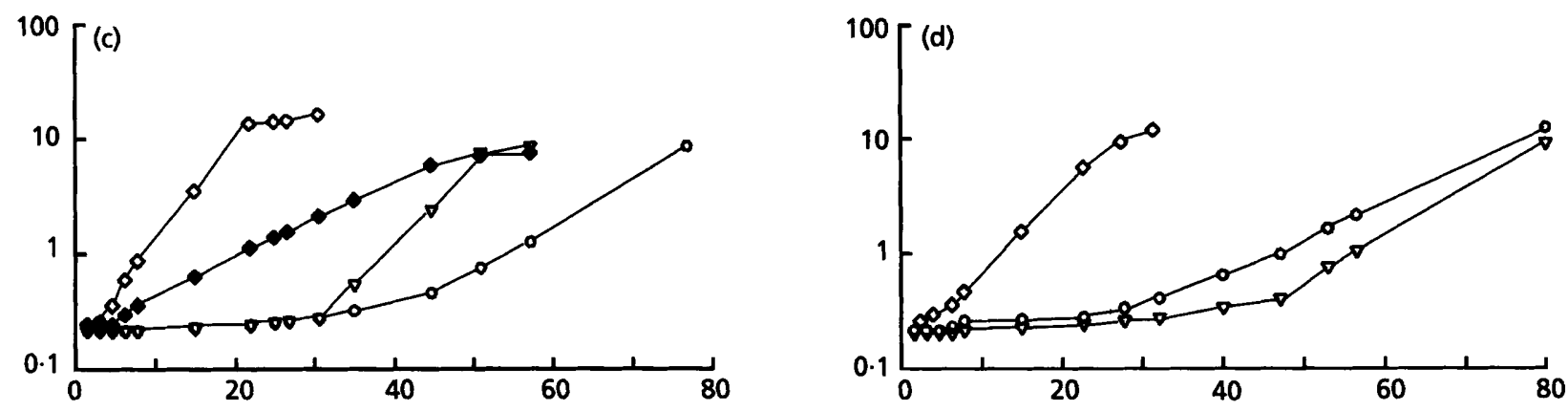

Time $(h)$

Fig. 3. Kinetics of derepression/induction. Strains KD-45B rho ${ }^{+}(\diamond), K_{D}-45 B$ rho- $(\diamond), \Delta T 1(\nabla)$ and $\Delta T 2(O)$ were grown to mid-exponential phase on YP at high glucose $(5 \%, w / v)$ and then shifted to $2 \%(w / v)$ raffinose (a), galactose (b), maltose (c) and ethanol (d). Samples were taken at the indicated time points for $\mathrm{OD}_{600}$ measurements. 
Table 2. Enzyme activities of glucose-repressible enzymes during derepression

Enzyme units are expressed in nmol substrate $\min ^{-1}(\mathrm{mg} \text { protein })^{-1}$. All values are means of three independent experiments. In no case was the variation higher than $15 \%$.

\begin{tabular}{|c|c|c|c|c|c|c|c|c|c|c|c|c|}
\hline \multirow{2}{*}{$\begin{array}{l}\text { Relevant } \\
\text { genotype }\end{array}$} & \multicolumn{3}{|c|}{ Maltase } & \multicolumn{3}{|c|}{ L-LCR } & \multicolumn{3}{|c|}{ NAD-GDH } & \multicolumn{3}{|c|}{ ADH } \\
\hline & HG* & $\mathbf{M} \dagger$ & $\mathbf{M} \ddagger$ & HG* & $\mathbf{L G}+$ & LG $\ddagger$ & HG* & $\mathbf{L G}+$ & $\mathbf{L G} \neq$ & HG* & $\mathbf{E} \dagger$ & $\mathbf{E} \ddagger$ \\
\hline IMP2 & 0 & 993 & 3644 & 3 & 92 & 128 & 25 & 114 & 166 & 390 & 1638 & 28058 \\
\hline $\operatorname{imp} 2-\Delta \mathrm{T} 1:: L E U 2$ & 0 & 0 & 3846 & 2 & 95 & 103 & 25 & 229 & 343 & 413 & 231 & 27802 \\
\hline imp 2- $\Delta \mathrm{T} 2:: L E U 2$ & 0 & 0 & 2612 & 6 & 100 & 117 & 13 & 213 & 369 & 370 & 155 & 21998 \\
\hline
\end{tabular}

* Cells grown with $5 \%(\mathrm{w} / \mathrm{v})$ glucose $(\mathrm{HG})$ were harvested during exponential phase and enzyme activities determined.

† Cells grown with $5 \%$ glucose were transferred on $2 \%$ maltose (M), $2 \%$ ethanol (E) or $0.1 \%$ glucose (LG); 4 h after the transfer cells were collected, crude extracts prepared and enzymic activities determined.

$\ddagger$ Cells were harvested during exponential growth on $2 \%$ maltose (M), $2 \%$ ethanol (E) or $0 \cdot 1 \%$ glucose (LG).

Table 3. Secreted invertase activity during glucose derepression

All values are means of three independent experiments. In no case was the variation higher than $15 \%$.

\begin{tabular}{|c|c|c|c|c|c|c|}
\hline \multirow[t]{2}{*}{$\begin{array}{l}\text { Relevant } \\
\text { genotype }\end{array}$} & \multirow{2}{*}{$\begin{array}{c}\text { Time } \\
\text { after } \\
\text { transfer } \\
\text { (h)* }\end{array}$} & \multicolumn{5}{|c|}{$\begin{array}{l}\text { Secreted invertase activity } \\
{\left[\text { [nmol } \mathrm{min}^{-1}\right.} \\
\left.(\mathrm{mg} \text { dry weight })^{-1}\right]\end{array}$} \\
\hline & & HG & LG $\ddagger$ & $\mathbf{R} \ddagger$ & Ga $\ddagger$ & $\mathbf{E} \ddagger$ \\
\hline \multirow[t]{3}{*}{$I M P 2$} & 2 & 0 & 66 & 59 & 56 & 43 \\
\hline & 4 & & 110 & 102 & 99 & 72 \\
\hline & 6 & & 108 & 113 & 98 & 112 \\
\hline \multirow{3}{*}{$i m p 2-\Delta \mathrm{T} 1::$ LEU2 } & 2 & 0 & 31 & 0 & 0 & 0 \\
\hline & 4 & & 33 & 0 & 0 & 0 \\
\hline & 6 & & 26 & 0 & 0 & 0 \\
\hline \multirow[t]{3}{*}{$\operatorname{imp} 2-\Delta \mathrm{T} 2:: L E U 2$} & 2 & 0 & 21 & 0 & 0 & 7 \\
\hline & 4 & & 29 & 0 & 0 & 14 \\
\hline & 6 & & 25 & 0 & 0 & 19 \\
\hline
\end{tabular}

* At these times the cells were collected and extracellular invertase was assayed.

†Cells grown with $5 \%(\mathrm{w} / \mathrm{v})$ glucose $(\mathrm{HG})$ were harvested during exponential phase and enzymic activities determined.

$\ddagger$ Cells grown with $5 \%$ glucose were transferred to a medium containing $0 \cdot 1 \%$ glucose (LG), raffinose (R), galactose $(\mathrm{Ga})$ or ethanol (E).

(Fig. 3a, b, c, respectively). Noticeably, the latter two delay times of the $r b 0^{-}$mutant are considerably shorter than the corresponding values for both imp2 mutants.

\section{Effect of different imp2 alleles on the expression of glucose-repressible enzymes}

The effect of glucose deprivation on the levels of maltase, L-LCR, NAD-GDH, ADH and secreted invertase was examined.

Induction of maltase requires a shift from high glucose to maltose (Vanoni et al., 1989). In contrast to wild-type cells, no maltase activity was detectable in either mutant $4 \mathrm{~h}$ after the transfer (Table 2). Maltase was eventually expressed, albeit with different delays, and it could be detected in both mutant strains during exponential growth on $2 \%$ maltose. Its activity in strain $\Delta \mathrm{T} 2$ was reduced by about $30 \%$ compared to strain $\Delta \mathrm{T} 1$ and the parental strain (Table 2).

L-LCR activity is detectable under nonrepressing conditions (low glucose, ethanol), induced by lactate and repressed by glucose (Somlo, 1965; Lodi \& Guiard, 1991). As shown in Table 2, no marked differences in LLCR activity were observed between mutants and wildtype cells first grown at high glucose $(5 \%)$ and then shifted to a low glucose medium $(0.1 \%$, a nonrepressing/ noninducing condition).

We determined cytoplasmic ADH activity in cell-free extracts from mutants and wild-type strains along the transition from a high glucose medium to an ethanolsupplemented medium. Under these two distinct experimental conditions, the activity measured at high glucose can be ascribed to fermentative ADH1, the cytoplasmic isoenzyme preferentially expressed in the presence of glucose (Denis et al., 1983), whereas any increase of activity observed upon shifting to an ethanol medium would result from derepression of oxidative ADH2 (Denis et al., 1983), the cytoplasmic isoenzyme repressed by glucose and induced by ethanol and glycerol (Lutstorf \& Megnet, 1968). Comparable levels of ADH activity were present in all strains at a high glucose concentration (Table 2). In contrast, a differential response was observed $4 \mathrm{~h}$ after shifting to an ethanolsupplemented medium. Under these conditions, ADH activity increased in the wild-type KD-45B, whereas it was appreciably lower in cell extracts from either mutant. During exponential growth on $2 \%$ ethanol, the levels of $\mathrm{ADH}$ activity were high and very similar in $\Delta \mathrm{T} 1$ and wildtype strains, although the enzyme activity of strain $\Delta \mathrm{T} 2$ was $20 \%$ down.

NAD-GDH is a key enzyme that catalyses the oxidative deamination of glutamate to ammonia thus providing a link between nitrogen and carbon metabolism. This 
(a)

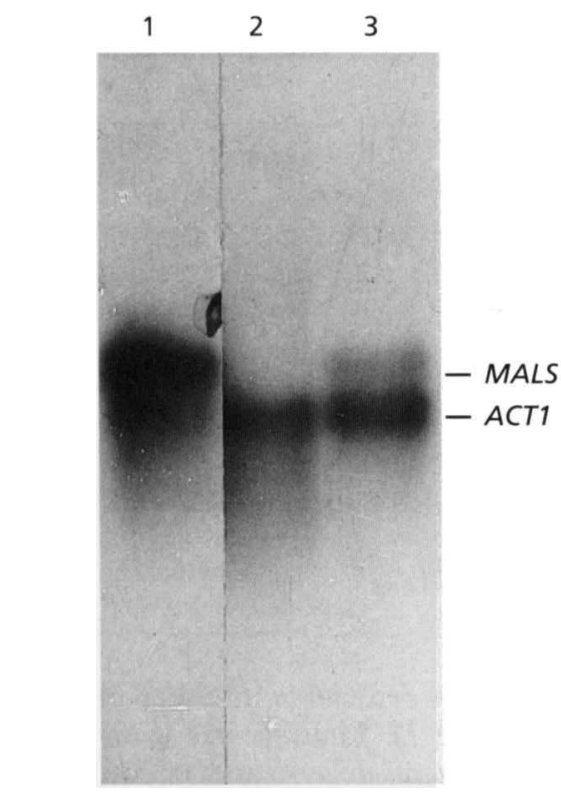

(b)

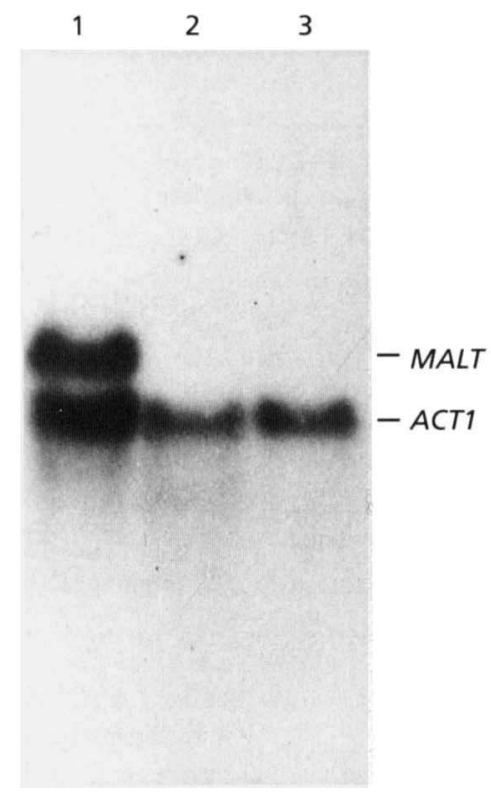

(c)

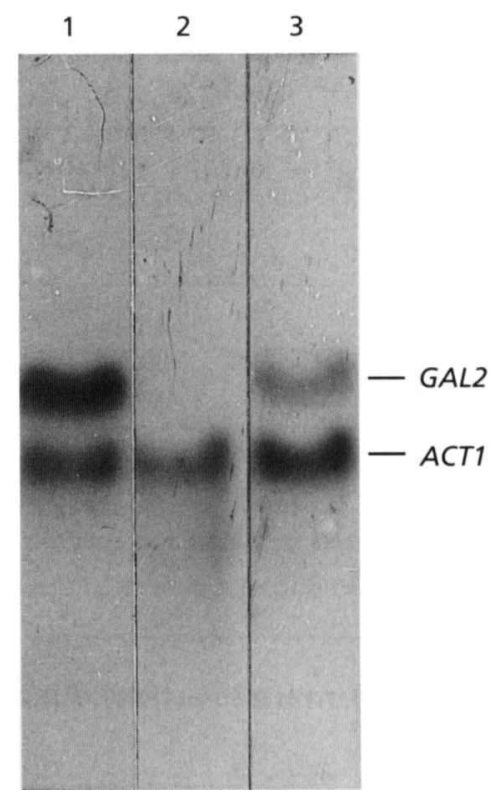

Fig. 4. DNA:RNA blot analysis. Strains KD-45B (lane 1), $\Delta T 1$ (lane 2) and $\Delta T 2$ (lane 3) were grown in YP at high glucose $(5 \%, w / v)$ to mid-exponential phase and then shifted to maltose $(a, b)$ and galactose (c) for $4 \mathrm{~h}$. Total RNA was then extracted and $20 \mu \mathrm{g}$ was loaded in each lane. Hybridizations were carried out with MALS (encoding maltase) in (a), MALT (encoding maltose permease) in (b) and GAL2 (encoding galactose permease) in (c). Hybridizations were also performed to detect transcripts from the actin gene (ACT1) as a control.

enzyme activity is controlled via a nitrogen circuit as well as through carbon catabolite repression (Holzer \& Schneider, 1957; Eraso \& Gancedo, 1984; Miller \& Magasanik, 1990). We tested the influence of IMP2 on the glucose regulatory circuit of NAD-GDH by transferring both wild-type and mutants cells pregrown on high glucose to a low glucose $(0 \cdot 1 \%)$ medium. As shown in Table 2 , the enzyme was similarly repressed by high glucose in all strains. Twice as much NAD-GDH activity was found in the mutants as compared to the wild-type strain upon derepression and this ratio was maintained during exponential growth on low glucose.

The activity of the secreted enzyme invertase, whose synthesis is only regulated by glucose repression (Carlson \& Botstein, 1982), was analysed in whole cells (either wild-type and mutants) transferred from high glucose medium $(5 \%)$ to low glucose $(0 \cdot 1 \%)$. As shown in Table 3 , invertase activity was detectable $2 \mathrm{~h}$ after switching in both mutants though at lower activity values than in the parental strain. We then examined the possibility that a long adaptive lag, with respect to invertase derepression, occurred when either mutant strain was switched from a high glucose to a raffinose-supplemented medium. Both mutants failed to express invertase activity during the first $6 \mathrm{~h}$ after transfer to the raffinose medium and a similar defect was also evident in the case of a shift to galactose (Table 3). Surprisingly, upon transfer to ethanolsupplemented medium strain $\Delta \mathrm{T} 2$, but not strain $\Delta \mathrm{T} 1$, derepressed invertase activity to a final level corresponding to about one-sixth of the activity of the wild-type KD45B strain (Table 3). Derepression of secreted invertase thus appears to depend on the carbon source and on the allelic status of the IMP2 gene. In contrast, roughly similar levels of invertase activity were measured in both mutant and wild-type strains during exponential growth on all of the carbon sources we tested (data not shown).

\section{IMP2 is required for derepression of GAL2, MALS and MALT genes}

To investigate a possible regulatory role of IMP2 at the transcriptional level, we examined the expression of three genes involved in sugar utilization by DNA:RNA hybridization.

The utilization of the disaccharide maltose depends on any one of five unlinked loci (MAL1-MAL4, MALG) (Vanoni et al., 1989) and in $\mathrm{Mal}^{+}$strains, maltase (MALS) and maltose transport activities (MALT) are coordinately induced by maltose and catabolite repressed by glucose (Vanoni et al., 1989). imp2 mutants were found to be defective in derepressing the $1.9 \mathrm{~kb}$ mRNA encoding maltase (Fig. 4a) and the $1.9 \mathrm{~kb}$ mRNA encoding maltose permease (Fig. $4 \mathrm{~b}$ ) within $4 \mathrm{~h}$ after transfer to maltose. It is also worth noting that trace amounts of maltase mRNA could be detected in strain $\Delta \mathrm{T} 2$, but not in the $\Delta \mathrm{T} 1$ mutant. Nevertheless, maltase activity was not detectable at this time (Table 2) nor $6 \mathrm{~h}$ after the transfer (data not shown) in cell extracts from either mutant.

Genes encoding enzymes involved in galactose catabolism (GAL1, GAL2, GAL3, GAL7 and GAL10) are transcriptionally repressed by glucose and induced by galactose 
(Johnston, 1987). Both mutants were unable to derepress the $1.7 \mathrm{~kb}$ mRNA corresponding to galactose permease (GAL2) $4 \mathrm{~h}$ after transfer to galactose (Fig. 4c). As in the case of maltase mRNA, traces of galactose permease mRNA could be detected in strain $\Delta \mathrm{T} 2$, but not in the strain $\triangle \mathrm{T} 1 \mathrm{RNA}$ preparation.

\section{DISCUSSION}

Glucose repression is a global regulatory mechanism that controls a large number of genes. Several elements involved in either glucose repression or derepression have been identified (for recent reviews see Gancedo, 1992; Johnston \& Carlson, 1992; Trumbly, 1992). IMP2 belongs to the latter group: it is required for the rapid glucose derepression of maltose, galactose, raffinose and ethanol utilization pathways. The finding that IMP2 contributes to, but is not absolutely required for, derepression of these pathways could indicate that a functionally redundant protein may partially compensate for the loss of IMP2. In particular, the inability to derepress these pathways in the presence of the antimitochondrial drugs EB and erythromycin when the IMP2 product is lacking implies that the level or functionality of this alternative activity may be limited somehow by the biosynthetic alteration of mitochondrial competence.

The steady state levels of the IMP2 transcript are not influenced either by the presence or absence of glucose in the culture medium in which the cells are grown or by the particular respiratory conditions. This indicates that IMP2 expression is regulated neither by catabolite repression nor by mitochondrial functioning.

To analyse the regulatory role of the IMP2 gene we constructed a deletant mutant $(\Delta \mathrm{T} 1)$ lacking the $\mathrm{C}$ terminal region coding for the last 26 amino acids. Since this mutant displayed a growth phenotype less dramatic than that of the previously isolated imp2-1 mutant a second completely deleted strain $(\Delta \mathrm{T} 2)$ was constructed. Its growth behaviour on different carbon sources was similar to the imp2-1 mutant. Sequence analysis of the imp2-1 mutant allele demonstrated that it carries a nonsense codon that reduces the protein to about a half. These results can explain why the phenotype of the imp2-1 mutant is more severe than that caused by the 26 amino acid $\mathrm{C}$-terminal deletion in mutant $\Delta \mathrm{T} 1$.

mRNA analysis data indicated that the IMP2 gene product appears to act positively to derepress transcription of maltase $(M A L S)$, maltose permease $(M A L T)$ and galactose permease (GAL2) genes. The precise mechanism of action remains to be established; however, delayed transcription of the GAL2, MALS and MALT genes upon derepression accounts for the absence of detectable levels of maltase, as well as for various defects observed with mutant cells during growth resumption in the presence of either galactose or maltose.

An intriguing result concerns the different behaviour of the two mutants with respect to: (i) invertase derepression in ethanol-supplemented medium (Table 3); (ii) adaptive lags after transfer to ethanol (Fig. 3d); and (iii) amounts of maltase and galactose permease mRNAs measured $4 \mathrm{~h}$ after shifting from high glucose to maltose and galactose, respectively (Fig. 4a, c). In all the above cases the partial modification of the gene product causes more dramatic effects than its complete absence. A possible working hypothesis is that the IMP2 gene product may function as a part of a larger protein complex. According to this model, the absence of this component could alter the complex in a way that allows the expression of some genes, perhaps as a consequence of changes in the binding affinity to DNA.

It is worth noting that both mutants were unable to quickly derepress invertase on either raffinose and galactose, but were able to derepress the enzyme when transferred to a low-glucose medium, albeit at levels lower than the wild-type. The levels of repressible enzymic activities, even those that reach a peak in the presence of an inducer such as L-LCR, are usually higher after a shift on low glucose than on other carbon sources (data not shown), probably due to the better energetic contribution. The increase in invertase activity to maximal levels within the first $6 \mathrm{~h}$ after transfer to a low glucose medium in the IMP2 strain, coupled with low levels of invertase in the two mutants under the same conditions, is consistent with the possibility that alterations of the hypothesized complex may allow gene expression. The inability of imp2 mutants to rapidly derepress both invertase on raffinose and oxidative $\mathrm{ADH}$ on ethanol can account for the long lags observed after the shift to these carbon sources.

NAD-GDH is regulated by IMP2 in an opposite way to other enzymes; in fact, its activity is present at levels higher than the wild-type in imp2 mutants. We thus conclude that the IMP2 gene product may be involved not only in positive, but also in negative regulation. Regulatory proteins exerting both positive and negative effects on gene expression are well documented (for reviews see Herskowitz, 1989; Verdier, 1990). Moreover, carbon catabolite repression mutants of $S$. cerevisiae have been described which at high glucose are concomitantly hyper-repressed for mitochondrial functions such as LLCR, D-lactate:ferricytochrome- $c$ oxidoreductase and cytochrome $a a_{3}$, and derepressed for NAD-GDH (Donnini et al., 1990).

IMP2 does not control derepression of the nuclear gene encoding the glucose-repressible mitochondrial enzyme L-LCR, indicating that the former gene does not play a general role in catabolite repression.

The effect of $i m p 2$ mutations on sugar utilization could result from its influence on mitochondrial function. Indeed, mitochondrial mutants have an impaired capacity for sugar utilization (Mahler \& Wilkie, 1978; Wilkie et al., 1983) and we cannot exclude that IMP2 may also regulate mitochondrial functions. Nevertheless, the stronger impact of imp2 mutations with respect to $r b^{-}$mutation during adaptation to galactose and maltose growth argues that the action of IMP2 can not be simply ascribed to an effect on mitochondrial competence, if any, but rather involves a direct effect on the expression of specific genes. 
The finding that imp2 partially impairs growth on lactate and glycerol (Donnini et al., 1992b) but not on ethanol (this study) could be due to a different contribution of the IMP2 gene product to the transcriptional control of glucose-repressible genes involved in the utilization of these carbon sources. However, the wild-type parental strains utilize ethanol more efficiently than glycerol and lactate. The better energetic contribution of ethanol could counterbalance an eventual effect of imp2 mutation.

The results of the present work demonstrate that IMP2 has a role in the derepression of a number of genes. However, the fact that imp2 mutants (i) are defective in both sporulation and heat-shock sensitivity (Donnini et al., 1992b), (ii) are more sensitive to biosynthetic mitochondrial inhibitors also on glucose and (iii) have levels of NAD-GDH activity higher than those of the parental strain strongly argue that the IMP2 gene product is involved in other regulatory functions besides derepression.

\section{ACKNOWLEDGEMENTS}

We thank P. P. Puglisi for helpful suggestions and S. Ottonello for critical comments on the manuscript. We also thank M. Vanoni for providing $M A L S$ and $M A L T$ probes and F. Lacroute and B. Guiard for providing pFL44 and Yep13 plasmids, respectively. This work was supported by a MURST $40 \%$ grant.

\section{REFERENCES}

Algeri, A. A., Bianchi, L., Viola, A. M., Puglisi, P. P. \& Marmiroli, N. (1981). IMP1/imp1: a gene involved in the nucleo-mitochondrial control of galactose fermentation in Saccharomyces cerevisiae. Genetics 97, 27-44.

Attardi, G. \& Schatz, G. (1988). Biogenesis of mitochondria. Annu Rev Cell Biol 4, 289-333.

Carlson, M. \& Botstein, D. (1982). Two differentially regulated mRNAs with different $5^{\prime}$ ends encode secreted and intracellular forms of yeast invertase. Cell 28, 145-154.

Casadaban, M. J., Martinez-Arias, A., Shapira, S. K. \& Chou, J. (1983). $\beta$-Galactosidase gene fusions for analysing gene expression in Escherichia coli and yeast. Methods Envymol 100, 293-308.

Celenza, J. L. \& Carlson, M. (1984). Cloning and genetic mapping of $S N F 1$, a gene required for expression of glucose-repressible genes in Saccharomyces cerevisiae. Mol Cell Biol 4, 49-53.

Denis, C. L., Ferguson, J. \& Young, E. T. (1983). mRNA levels for the fermentative alcohol dehydrogenase of Saccharomyces cerevisiae decrease upon growth on a non fermentable carbon source. J Biol Chem 25, 1165-1171.

Donnini, C., Goffrini, P., Rossi, C. \& Ferrero, I. (1990). Isolation and characterization of carbon catabolite repression mutants in Saccharomyces cerevisiae. Microbiologica 13, 283-295.

Donnini, C., Lodi, T., Ferrero, I., Algeri, A. A. \& Puglisi, P. P. (1992a). Allelism of IMP1 and GAL2 genes of Saccbaromyces cerevisiae. J Bacteriol 174, 3411-3415.

Donnini, C., Lodi, T., Ferrero, I. \& Puglisi, P. P. (1992b). IMP2, a nuclear gene controlling the mitochondrial dependence of galactose, maltose and raffinose utilization in Saccharomyces cerevisiae. Yeast 8, 83-93.
Eraso, P. \& Gancedo, J. M. (1984). Catabolite repression in yeasts is not associated with low levels of cAMP. Eur $J$ Biochem 141, 195-198.

Ferrero, I., Rambaldelli, R., Genga, A. M., Donnini, C. \& Puglisi, P.P. (1984). $A L G / a l g$ : a single gene controlling the utilization of lactate in the presence of antimycin in the yeast Saccharomyces cerevisiae. Curr Genet 8, 407-411.

Gancedo, J. M. (1992). Carbon catabolite repression in yeast. Eur J Biochem 206, 297-313.

Goldstein, A. \& Lampen, J. O. (1975). $\beta$-D-Fructofuranoside fructohydrolase from yeast. Methods Enzymol 42, 504-511.

Grisolia, S., Quisado, C. L. \& Fernandez, M. (1964). Glutamate dehydrogenase from yeast and animal tissue. Biochim Biopbys Acta 81, 61-70.

Grivell, L. A. (1989). Nucleo-mitochondrial interactions in yeast mitochondrial biogenesis. Eur J Biochem 182, 477-493.

Hanson, A. D. \& Jacobsen, J. V. (1984). Control of lactate dehydrogenase, lactate glycolysis, and $\alpha$-amylase by $\mathrm{O}_{2}$ deficit in barley aleurone layers. Plant Physiol 75, 566-572.

Herskowitz, I. (1989). A regulatory hierarchy for cell specialization in yeast. Nature 342, 749-757.

Holzer, H. \& Schneider, S. (1957). Anreicherung und Trennung einer DPN-spezifischen und einer TPN-spezifischen Glutaminosaure Dehydrogenase aus Hefe. Biochem Z 329, 361-367.

Ito, H., Fukada, Y., Murata, K. \& Kimura, A. (1983). Transformation of intact cells treated with alkali cations. J Bacteriol 153, 163-168.

Johnston, M. (1987). A model fungal gene regulatory mechanism: the GAL genes of Saccharomyces cerevisiae. Microbiol Rev 51, 458-476.

Johnston, M. \& Carlson, M. (1992). Regulation of carbon and phosphate utilization. In The Molecular and Cellular Biology of the Yeast Saccharomyces. Gene Expression, vol. 2, pp. 193-281. Edited by E. W. Jones, J. R. Pringle \& J. R. Broach. Cold Spring Harbor, NY: Cold Spring Harbor Laboratory.

Liao, X. \& Butow, R. A. (1993). RTG1 and RTG2: two yeast genes required for a novel path of communication from mitochondria to the nucleus. Cell 72, 61-71.

Lodi, T. \& Guiard, B. (1991). Complex transcriptional regulation of the Saccharomyces cerevisiae CYB2 gene encoding cytochrome b2: $C Y P 1(H A P 1)$ activator binds to the $C Y B 2$ upstream activation site UAS1-B2. Mol Cell Biol 11, 3762-3772.

Lutstorf, U. \& Megnet, R. (1968). Multiple forms of alcohol dehydrogenase in $S$. cerevisiae. Physiological control of $A D H 2$ and properties of $A D H 2$ and ADH4. Arch Biochem Biophys 126, 933-944.

Mahler, H. R. \& Wilkie, D. (1978). Mitochondrial control in the sugar utilization in Saccharomyces cerevisiae. Plasmid 1, 125-133.

Mandel, H. \& Higa, A. (1970). Calcium dependent bacteriophage DNA infection. $J$ Mol Biol 53, 159-162.

Maniatis, T., Fritsch, E. F. \& Sambrook, J. (1982). Molecular Cloning: a Laboratory Manual. Cold Spring Harbor, NY: Cold Spring Harbor Laboratory.

Miller, S. M. \& Magasanik, B. (1990). Role of NAD-linked glutamate dehydrogenase in nitrogen metabolism in Saccharomyces cerevisiae. J Bacteriol 172, 4927-4935.

Nasmyth, K. A. \& Reed, S. I. (1980). Isolation of genes by complementation in yeast: molecular cloning of a cell-cycle gene. Proc Natl Acad Sci US A 77, 2119-2121.

Parikh, V. S., Morgan, M. M., Scott, R., Clement, L. S. \& Butow, R. A. (1987). The mitochondrial genotype can influence nuclear gene expression in yeast. Science 235, 576-580. 
Partaledis, J. A. \& Mason, T. L. (1988). Structure and regulation of a nuclear gene in Saccharomyces cerevisiae that specifies MPR13, a protein of the small subunit of the mitochondrial ribosome. Mol Cell Biol 8, 3647-3660.

Sanger, F., Nicklen, S. \& Coulson, A. R. (1977). DNA sequencing with chain-terminating inhibitors. Proc Natl Acad Sci USA 74, 5463-5467.

Sherman, F., Fink, G. R. \& Hicks, J. B. (1982). Methods in Yeast Genetics. Cold Spring Harbor, NY: Cold Spring Harbor Laboratory.

Somlo, M. (1965). Induction des lactico-cytochrome c reductases (D- et L-) de la levure aérobie par des lactates (D- et L-). Biocbim Biophys Acta 97, 183-201.

Trumbly, R. J. (1992). Glucose repression in the yeast Saccharomyces cerevisiae. Mol Microbiol 6, 15-21.

Tzagoloff, A. \& Dieckmann, C. L. (1990). PET genes of Saccharomyces cerevisiae. Microbiol Rev 54, 211-225.

Vanoni, M., Sollitti, P., Goldenthal, M. \& Marmur, J. (1989). Structure and regulation of the multigene family controlling maltose fermentation in budding yeast. Prog Nucleic Acid Res Mol Biol 37, 281-322.

Verdier, J. M. (1990). Regulatory DNA-binding proteins in yeast: an overview. Yeast 6, 271-297.

de Vries, S. \& Marres, C. A. M. (1987). The mitochondrial respiratory chain of yeast. Structure and biosynthesis and the role in cellular metabolism. Biocbim Biopbys Acta 895, 205-239.

Wang, S. S. \& Brandriss, M. C. (1987). Proline utilization in Saccharomyces cerevisiae: sequence, regulation, and mitochondrial localization of the PUT1 gene product. Mol Cell Biol 7, 4431-4440.

Wilkie, D., Evans, I. H., Egilsonn, V., Diala, E. S. \& Collier, D. (1983). Mitochondria, cell surface, and carcinogenesis. Int Rev Cytol Suppl 15, 157-189.

Zimmermann, F. K., Kaufmann, I., Rosemberger, H. \& Hausmann, P. (1977). Mutants of Saccharomyces cerevisiae resistant to carbon catabolite repression. Mol \& Gen Genet 154, 75-82.

Received 28 February 1995; revised 4 May 1995; accepted 12 May 1995. 